\title{
O CONCEITO DE QUALIDADE NA EDUCAÇÃO ARTICULAÇÕES E REARTICULAÇÕES NAS DISPUTAS POR HEGEMONIA
}

\author{
THE QUALITY CONCEPT IN EDUCATION: JOINTS AND REARTICULATIONS THE \\ HEGEMONY DISPUTES \\ EL CONCEPTO DE CALIDAD EN LA EDUCACIÓN: ARTICULACIONES Y NUEVAS \\ ARTICULACIONES EN LAS DISPUTAS POR LA HEGEMONÍA.
}

\author{
Ricardo Boklis Golbspan* \\ Mestrando em Educação UFRGS | Brasil \\ E-mail: ricardo.golbspan@gmail.com
}

Luís Armando Gandin**

Doutor (PhD) em Educação pela University of Wisconsin-Madison | EUA E-mail: luis.gandin@ufrgs.br

\begin{abstract}
REVISTA PEDAGÓGICA
Revista do Programa de Pós-graduação em Educação da Unochapecó | ISSN 1984-1566 Universidade Comunitária da Região de Chapecó | Chapecó-SC, Brasil Como referenciar este artigo: GOLBSPAN, R. B. GANDIN, L. A. O conceito de qualidade na educação: articulações e rearticulações nas disputas por hegemonia. Revista Pedagógica, Chapecó, v.16, n.32, p. 49-63, jan./jul. 2014.
\end{abstract}

RESUMO: Este artigo analisa como o conceito de qualidade na educação tem sido hegemonicamente definido. Na primeira parte, apresenta-se o método de Bakhtin sobre a análise de palavras para justificar o estudo do conceito de qualidade. Na segunda parte, discute-se como o conceito de qualidade aparece no contexto educacional em função das transformações sociais históricas. Finalmente, contextualizamos o debate sobre qualidade de educação com as recentes modernizações de Estado.

PALAVRAS-CHAVE: Qualidade. Bakhtin. Análise Relacional. Terceira Via.
ABSTRACT: This paper analyzes how the concept of quality in education has been hegemonically defined. In the first part, it introduces Bakhtin's method of analysis of words, explaining the analysis on the concept of quality and on the journalistic discourse. In the second part, it discusses how the concept of quality in education appears according to historic social transformations. Finally, it contextualizes the current debate on quality within the recent State modernizations.

KEYWORDS: Quality. Bakhtin. Relational Analysis. Third Way. 


\begin{abstract}
* Mestrando em Educação UFRGS. Bolsista CAPES.

** Doutor (PhD) em Educação pela University of Wisconsin-Madison e professor da Faculdade de Educação e do Programa de Pós-Graduação em Educação da Universidade Federal do Rio Grande do Sul. É Editor-Chefe de Educação \& Realidade, Editor de Currículo sem Fronteiras (Portugal/Brasil) e Editor para a Língua Portuguesa de Education Policy Analysis Archives (Estados Unidos).
\end{abstract}

\section{INTRODUÇÃO}

Qualidade, de acordo com Enguita (1995), tem sido um conceito amplamente escolhido para se referir aos avanços educacionais. Desta maneira, concepções muito diversas sobre os rumos que a educação deve tomar têm aparecido sob a mesma bandeira da qualidade, verificando-se particularmente que as articulações e rearticulações socialmente hegemônicas têm posicionado a educação eminentemente como uma ferramenta de desenvolvimento econômico no cenário de competição capitalista internacional. Neste sentido, analisar criticamente a definição de qualidade em educação ao longo dos últimos anos, a partir dos movimentos de modernização dos Estados, é uma forma de entender o que socialmente tem sido esperado das escolas, e de apresentar algumas possibilidades que têm sido imaginadas para os rumos da educação.

Neste artigo, propomos o uso da linguagem, segundo Bakhtin (2006), como método de uma análise relacional do conceito de qualidade, posicionando o atual debate social em torno do conceito, e verificando especificamente o processo de hegemonização do significado de qualidade. Primeiro, contextualizamos a obra de Bakhtin e justificamos a importância da análise crítica da palavra. Em seguida, discutimos como historicamente o conceito de qualidade apareceu em educação. Por fim, realizamos uma análise relacional (Apple, 2006) do conceito de qualidade na educação escolar a partir dos atuais processos de modernização do Estado e de suas consequências para a democratização da educação. Nosso objetivo é demonstrar as implicações educacionais da hegemonização de um significado de qualidade que posiciona a educação como indicador econômico e que aproxima a noção de boa educação ao modelo empresarial de qualidade.

\section{AS CONTRIBUIÇÕES DE BAKHTIN PARA A ANÁLISE DO CONCEITO DE QUALIDADE}

Envolto em controvérsias quanto a sua autoria ${ }^{1}$,

1 Segundo prefácio da edição consultada, o livro em questão, publicado com autoria de Volochínov, foi escrito em verdade por Bakhtin (Jakobson, 2006). Neste trabalho, estaremos de acordo com a edição consultada.

2 Todas as traduções do espanhol são nossas. mental neste exercício que propomos. O livro surpreende
Marxismo e Filosofia da Linguagem, lançado em duas edições (em 1929 e 1930) é o trabalho teoricamente fundapela originalidade de seu conteúdo, mesmo passados mais de 80 anos de sua publicação. É neste clássico, afinal, que se inaugura uma conexão entre os estudos linguísticos e o marxismo. Conforme Williams²:

A contribuição decisiva [de Bakhtin] foi encontrar um caminho além das poderosas, ainda que parciais, teorias da expressão e do sistema objetivo. Ele encontrou o caminho em termos fundamentalmente marxistas, ainda que começasse afirmando que o pensamento marxista a respeito da linguagem era praticamente inexistente. A sua originalidade está no feito de não procurar aplicar à linguagem outras ideias marxistas. Pelo contrário, 
reconsiderou todo o problema da linguagem dentro de uma orientação geral marxista. (Williams, 2000, p. 48).

Assim, a filosofia da linguagem introduzida por Bakhtin (2006) tem como objetivo explicar, a partir do marxismo, os fatos sociais. A sua constatação é essencialmente metodológica: a linguagem e os signos verbais, definidos como ideológicos pelo autor, são um local real em que ocorrem as disputas, os desencontros e os consensos da vida em sociedade:

Cada signo ideológico é não apenas um reflexo, uma sombra da realidade, mas também um fragmento material dessa realidade. Todo fenômeno que funciona como signo ideológico tem uma encarnação material, seja como som, como massa física, como cor, como movimento do corpo ou como outra coisa qualquer. (Bakhtin, 2006, p. 31).

Palavras, como qualidade, são signos especialmente destacados para Bakhtin (2006). Os signos, afinal, são os responsáveis pela materialização da comunicação social que é, para Bakhtin (2006), o meio pelo qual se define o contexto socioideológico - e, no estabelecimento da comunicação, é a linguagem a forma mais clara e completa em que aparece esse papel de contato constante entre diferentes signos. Desta maneira, a palavra é o fenômeno ideológico por excelência, pois existe exatamente para exercer a função de signo. Portanto, é dona de "excepcional nitidez semiótica” (Bakhtin, 2006, p. 34). Além da pureza semiótica, para Bakhtin (2006), uma diferença central entre a palavra e os demais signos é que ela é o único signo neutro. Todos os outros signos estão vinculados a um determinado material ideológico para o qual foi criado, e a esse material permanece inseparável. A palavra, pelo contrário, para o autor russo, pode preencher qualquer espécie de função ideológica, pois seu sentido (significado) depende sempre do contexto. A palavra é, materialmente, neutra, esvaziada ideologicamente e é moldada em relação de dependência com o contexto - que a preenche e, assim, sua neutralidade torna-se exatamente o oposto - a palavra passa a ser carregada de ideologia. Tal propriedade da palavra explica a flutuância da noção de qualidade educacional. Tem sido em nome da qualidade que ações e ideias políticas para a educação têm sido justificadas, por mais que sejam precisamente antagônicas. Um rápido exame de propostas de partidos políticos de situação e oposição, por exemplo, pode comprovar que todos querem uma educação de qualidade. O significado de qualidade que prevalecer em determinado contexto, porém, é o que definirá a compreensão da palavra, que é sempre neutra, sempre deslizante.

Outra característica importante da palavra é o fato de ela ser o recurso primeiro para a consciência individual: é ela - embora sua realidade, como de qualquer signo, resulte do convívio social - que expressa um discurso interior. 
A palavra traduz em forma de discurso, mesmo que interiormente, os fenômenos ideológicos, como uma dança, uma música, um ritual religioso, um gesto ou um comportamento humano qualquer. O mesmo vale para fenômenos ideológicos mais gerais, como o senso do que é hegemônico politicamente em uma determinada sociedade; é a palavra a melhor tradução da ideologia para a individualidade, é nela em que se manifesta a ideologia. Todo ato ideológico, portanto, está acompanhado das palavras em nível de consciência individual. Ela não substitui outros signos não verbais, pois não existem substitutos verbais adequados para esses signos. Porém, estes se apoiam em palavras e estão sempre acompanhados de palavras, em uma consciência verbalmente constituída. Segundo Bakhtin (2006, p. 36), "a palavra está presente em todos os atos de compreensão e em todos os atos de interpretação”. Por isso, as questões educacionais e os rumos que se têm pretendido para a educação só poderão ser compreendidos a partir da análise das palavras centrais do ambiente educacional, que explicam os atos ideológicos que ocorrem materialmente na educação, pois são elas que constituem a forma que o indivíduo social encontrou de explicar sua consciência, de materializar as noções que se hegemonizam socialmente.

Não se nega, aqui, a existência de uma consciência. O que Bakhtin (2006) explica é que toda a expressão consciente é provida de sentido, de significado e, portanto, é semiótica. Os pensamentos, as racionalizações e os diálogos, resultantes da atividade psíquica, são inseparáveis da sociedade e, desta maneira, não advêm simplesmente de um certo espírito, mas sim dos acordos sociais simbólicos que estruturam o pensamento individual. Um sentimento ou um instinto jamais seriam substituídos pelo discurso, este jamais daria conta de toda sua complexidade - todavia, é através dos signos que o indivíduo social é capaz de criar consciência quanto a si mesmo. Essa nova constatação ajuda a explicar que a alta ou a baixa qualidade educacional não é algo espiritual ou desenvolvido a partir das ideias, mas são as articulações das relações sociais concretas que serão decisivas quanto à noção que se tem individualmente de qualidade.

Enfim, o que a extensa obra de Bakhtin ensina, e que, de forma bastante recortada, procuramos ressaltar, é que analisar a palavra é uma maneira concreta de analisar a sociedade. Analisar a palavra qualidade no contexto educacional, portanto, é uma forma de entender o que se tem entendido amplamente como boa ou má educação.

Esse posicionamento da qualidade como um conceito que tem sua definição em disputa na educação, portanto, é o pressuposto metodológico de que partimos nesta análise. A complexa teoria de Bakhtin (2006) conecta-se com as disputas por hegemonia em educação, que passam invariavelmente pela comunicação linguística. Nosso obje- 
tivo agora é relacionar a filosofia da linguagem de Bakhtin (2006) com o conceito de qualidade na educação a partir das reorganizações dos Estados. Esse exame, mais histórico, será base, também, para a análise específica do contexto educacional atualmente, ao qual nos dedicaremos na sessão intitulada Atual configuração do Estado...

\section{HISTÓRICO DO CONCEITO DE QUALIDADE NA EDUCAÇÃ̃O}

Como procuramos demonstrar até aqui, é justamente através de palavras, que têm a característica de neutralidade, que as disputas ideológicas têm ocorrido na definição dos rumos da educação. Qualidade é uma das palavras que tem aparecido de forma significativa nesse jogo ideológico, conectando-se, atualmente, no senso comum, a noções hegemônicas ligadas à lógica de mercado. Essa fixação de qualidade a um significado hegemônico se dá através de articulações estruturais cotidianas, em termos econômicos ou culturais, e que vêm ocorrendo ao longo da história recente, desde que a palavra começou a aparecer no discurso educacional.

Esse processo se inicia com o conceito de qualidade sendo identificado com:

[...] a dotação em recursos humanos e ma-
teriais dos sistemas escolares ou suas partes
componentes: proporção do produto interno
bruto ou do gasto público dedicado à educa-
ção, custo por aluno, número de alunos por
professor, duração da formação ou nível sala-
rial dos professores, etc. Este enfoque corres-
pondia à forma pela qual, ao menos na época
florescente do Estado de Bem-Estar, se ten-
dia a medir a qualidade dos serviços públicos,
supondo que mais custo ou mais recursos,
materiais ou humanos, por usuário era igual
a maior qualidade. (Enguita, 1995, p. 98).

Essa concepção de qualidade popularizou-se principalmente nos países em que se verificaram Estados welfaristas, como os Estados Unidos e o Reino Unido, a partir do fim da Segunda Guerra Mundial até a crise de meados dos anos 1970. Os Estados de Bem-Estar Social (Clarke; Newman, 2006) originaram narrativas de coesão nacional em torno de noções como família, trabalho e nação. Nesse contexto, a construção organizacional do Estado de Bem-Estar Social britânico foi estruturada a partir de duas formas de coordenação: administração burocrática e profissionalismo, o que influenciou decisivamente na noção de qualidade em educação. A partir de uma lógica hierárquica burocrática foi possível superar parcialmente o anterior nepotismo e favorecimento político em nome de uma administração pública imparcial, e registrar produtos previsíveis e rotineiros, para que os cálculos fossem estáveis, previsíveis e supostamente neutros. Além disso, a expertise do profissionalismo dá conta da necessidade da intervenção de um julgamento técnico. O Estado de Bem-Estar Social, assim, 
desenvolveu-se a partir de uma dupla lógica de representação do público. De um lado, o conhecimento burocrático, a serviço do interesse público. E, de outro, o conhecimento profissional, que iria melhorar o bem público. Por isso, o conceito de qualidade em educação aparece inicialmente ligado a cálculos burocráticos - não no seu sentido pejorativo, mas sim no sentido de apresentar resultados estáveis e quantificáveis - alinhados à uma especialização em questões educativas mais relacionadas à prática pedagógica, como o estudo do custo por aluno ou da quantidade de alunos por professor, por exemplo. Com efeito, em resposta ao que se verificara no início do século, com o estabelecimento do taylorismo e a consequente incorporação do mundo do trabalho à linguagem escolar (Enguita, 1995), nos anos 1950 o tom do aumento da qualidade escolar passou a se conectar mais à defesa da democracia e à igualdade de oportunidades, ainda que em um contexto em que esses avanços seriam importantes como um investimento para o desenvolvimento nacional, através do reforço de disciplinas escolares importantes para o mundo empresarial e para a competição internacional da Guerra Fria, o que se estabeleceu até meados dos anos 1970, com a também crescente universalização do ensino público em nome também do desenvolvimento nacional.

A partir da década de 1970, no entanto, a Nova Direita na Inglaterra e nos Estados Unidos passou a contar de uma forma muito particular a história sobre as condições da crise econômica que se verificou à época e, assim, passou também a preparar o terreno para reformular as relações entre Estado e o bem-estar social (Clarke; Newman, 2006). Essa história foi construída a partir da crítica ao Estado vigente e da elaboração de uma solução ancorada no neoliberalismo, como renascimento do individualismo, e no neoconservadorismo, como revitalização da moral tradicional. O neoliberalismo na Inglaterra e nos Estados Unidos enfatizou a supremacia do mercado como um mecanismo de distribuição social de benefícios, serviços e renda, representando uma volta repaginada ao liberalismo em que as leis de mercado podem substituir o Estado. Conforme esse ponto de vista, o Estado seria um intruso nos negócios do mercado, distorceria o mercado com as crescentes taxas de impostos, vistas como inibidoras para a competitividade da nação, das companhias e dos indivíduos, com sua excessiva regulação do mercado, ou provendo benefícios de bem-estar que deixam de incentivar a busca pelo sucesso profissional. O neoliberalismo vê a provisão de serviços sociais como um impedimento para o que deveria ser a teoria da escolha pública. O monopólio do Estado em prover os serviços de bem-estar acaba não criando oportunidades para o usuário exercer a escolha como cliente de benefícios de bem-estar, que passam a ser vistos também como produtos de mercado - a forma, segundo esta crença, que pode dar resultados melhores em comparação com o Estado de 
Bem-Estar, que, afinal, seria o responsável pela eclosão da crise segundo a crença da Nova Direita. Essa provisão estatal do Estado de Bem-Estar contrasta com as leis de mercado nas quais a competição garantiria uma escolha efetiva por parte dos consumidores. Essa questão contribuiu para o segundo tema trazido à cena pela Nova Direita: o ataque neoconservador dos efeitos do Estado de Bem-Estar Social.

Os cidadãos que dependem dos serviços de Bem-Estar Social e de benefícios passaram, na visão insurgente da Nova Direita, a ser demonizados como parasitas, pois usavam contribuições públicas sem obrigações com uma responsabilização. O parasita é uma imagem na qual os discursos neoliberais e neoconservadores da Nova Direita se encontram, estabelecendo o encontro já exemplificado por Apple (2008) anteriormente para explicar a hegemonia. De fato, nesse momento da história vemos as alianças em ação em nome da conquista de hegemonia: o neoliberalismo vê o parasita como um produto inevitável dos benefícios do Estado de Bem-Estar Social, provendo incentivos para que este não aceite trabalhar como uma mão de obra barata; ao mesmo tempo, os neoconservadores criticam os efeitos desmoralizantes do provimento de benefícios pelo Estado de Bem-Estar Social, o que causa um colapso na cultura e na moralidade. Desse ponto de vista, uma moral tradicional, que é baseada nas responsabilidades pessoais e familiares, é solapada pela expectativa de provimento por parte do Estado, produzindo uma cultura de dependência. O colapso ou a desorganização familiar são vistas como um efeito desse processo da desmoralização colocado em prática por este Estado-provedor.

A Nova Direita na Inglaterra e nos Estados Unidos juntou as diferentes críticas para produzir uma grande mudança no consenso pós-guerra e no lugar simbólico que ocupava o Estado de Bem-Estar Social. Nesse processo, o Estado de Bem-Estar Social foi apontado como uma agência ativa no processo de declínio nacional. Uma vez que foi derrubado o consenso na antiga configuração de Estado, a Nova Direita criou a política mais ideológica e dogmática no período do pós-guerra (Clarke; Newman, 2006). Ao mesmo tempo, foi disseminada, no senso comum, a ideia de que apenas os outros eram dogmáticos. A Nova Direita colocou-se, nos anos de 1980 e 1990, ao lado do povo contra o Estado, mesmo que estivesse no governo durante esse período. Essa noção antiestadista da Nova Direita mostra como as instituições estatais do pós-guerra passaram a ser vistas como um impedimento para a reorganização da nação como uma sociedade competitiva e empreendedora.

Esse contexto histórico, no campo educacional, influenciou as expectativas quanto à escola, que deveria cumprir com os objetivos sociais mais amplos ligados à competitividade, tanto interna quanto externamente, e ao empreendedorismo. $\mathrm{O}$ foco da atenção do conceito de qua- 
lidade da educação deslocou-se, pois, dos recursos e insumos para a eficácia do processo: conseguir o máximo de resultado ao mínimo de custo (Enguita, 1995). Passou-se a avaliar a qualidade da educação a partir de resultados obtidos em pesquisas e testes, como taxas de retenção, taxas de aprovação, comparações internacionais de rendimento escolar etc. No entanto, mesmo com essas alterações a partir da crise do Estado de Bem-Estar e com a ascensão da Nova Direita, essa nova versão de qualidade não substitui inteiramente as versões anteriores - ou as versões contra-hegemônicas que circulam simultaneamente -, e é precisamente isso, essa impossível fixação de significado, que permite que diferentes grupos com interesses distintos possam coincidir em torno de uma mesma palavra para justificar suas atitudes e planos, o que leva à formação de alianças (da linguagem de eficiência do neoliberalismo com as noções conservadoras nacionais), à formação de uma realidade pública nuançada ou contraditória (heranças da burocracia em combinação com a nova lógica da Nova Direita), assim como à formação de resistências e projetos contra-hegemônicos.

A centralidade atual em torno especificamente da qualidade, também, decorre em grande parte desses movimentos do Estado desde os anos 1970 e 1980. Levantava-se o grito pelas altas taxas de evasão, os maus resultados em comparação com outros países (um fenômeno internacional de insatisfação, pois sempre há índices em que se vai mal) e uma suposta queda de nível em relação ao passado. O neoconservadorismo e a busca por um passado supostamente glorioso encontravam na excelência de desempenho da lógica de mercado a solução para uma educação de qualidade. Simultaneamente, o declínio do socialismo burocrático dos países do Leste europeu levou o discurso da reforma educacional ainda mais ao campo da eficiência, deixando de lado a questão da igualdade e da democracia (Enguita, 1995).

Enquanto isso, na América Latina, o discurso de qualidade no campo educacional começou a se desenvolver no final dos anos 1980 como contraface do discurso de democratização (Gentili, 1995). Segundo Gentili (1995), na América Latina o termo qualidade era empregado em setores produtivos e passou a ser utilizado em educação exatamente em função dos ataques neoliberais e neoconservadores ao sistema educacional público. O termo passou a ser utilizado para conter as demandas democratizantes resultantes do fim das ditaduras da região. Desta forma, aparecendo no discurso hegemônico como tradução do que seria uma escola melhor, essa noção de qualidade filiada ao mundo empresarial não apenas levou a lógica de mercado à escola, como foi recurso para impedir um processo democratizante na educação latino-americana.

Aqui, chamamos a atenção para a volatilidade de outro significante além da qualidade, a democracia (Hall, 
2003). Esse significante pode ser expresso para se referir ao senso de democracia mencionado por Gentili (1995), que dê conta de uma vitória das classes populares, ou para se referir a uma democracia capitalista, que foi o resultado do processo de democratização pós-ditadura na América Latina. Para Gentili (1995), a democracia que se instaurou é uma democracia não democrática, que não apresentou avanços econômicos, reforçou um padrão de distribuição de renda injusto e seguiu legitimando a exclusão social.

Para o autor, o debate acadêmico sobre os rumos da educação passou, durante os anos 1980 e 1990, por quatro etapas: uma preocupação inicial de análise de modelos teóricos, buscando combater o reprodutivismo na educação; posteriormente, pela preocupação com a democratização da educação, durante o triênio 83-85, discutindo como superar o autoritarismo recentemente vencido na região; em um terceiro momento, considerada "a preocupação mais sofisticada e rigorosa que pretendeu abordar o campo acadêmico neste período" (Gentili, 1995, p. 123), buscou-se a democratização com qualidade; num quarto momento, porém, o termo qualidade já aparecia fixado ao significado mercadológico, em que qualidade educacional se conecta à eficiência e produtividade, e assim a racionalidade empresarial passou a ser matriz ideológica dos rumos da educação.

Deste modo, dado o caráter novamente reforçado de flutuância da definição de qualidade e o relato da trajetória do conceito, já com pinceladas de seu uso atual, propomos agora a descrição das correntes mudanças do Estado e dos efeitos dessas modernizações para a noção de qualidade.

\section{ATUAL CONFIGURAÇÃO DO ESTADO E IMPLICAÇÕES PARA O CONCEITO DE QUALIDADE}

Para analisarmos as articulações da disputa por hegemonia do significado de qualidade em educação, procuramos agora apresentar os recentes movimentos de modernização do Estado, em particular no âmbito da educação. Essa análise é importante porque é a explicação central que propomos das causas e da forma como a disputa pela hegemonia em educação, e pela noção de qualidade educacional, vem ocorrendo atualmente na sociedade.

Nessa perspectiva, o principal movimento recente de modernização do Estado que tem influenciado os rumos da educação está relacionado ao que Peroni (2013) identificou como um duplo movimento de mudanças no papel do Estado atual: o primeiro é a alteração de propriedade, ocorrendo a passagem do estatal para o privado ou para o público não estatal; o segundo movimento é a permanência da propriedade pública, mas com a incorporação do ethos de mercado na organização institucional da gestão pública. Esses dois movimentos são entre si determinantes, constituindo, em conjunto, o que tem sido definido como 
Terceira Via (Peroni, 2013). Dentro desses movimentos, é possível posicionar novos atores, novos discursos, novos interesses e novo jeito de operar, e também é possível imaginar os rumos que essas novas configurações têm traçado para a educação.

Simultaneamente à solução neoliberal, portanto, tem se estabelecido uma nova social-democracia, que, conforme um de seus teóricos, Anthony Giddens (2001, p. 36), trata-se de "uma tentativa de transcender tanto a social-democracia do velho estilo quanto o neoliberalismo". No programa da Terceira Via, assim, diferente da proposta neoliberal, o Estado não deve ser mínimo, mas sim reformado. No entanto, como o diagnóstico também é de que o Estado é ineficiente, ele deve ser reformado tendo como parâmetro o mercado. Dentro dessa reforma, o programa da Terceira Via propõe que as políticas sociais fiquem a cargo da sociedade civil, através das figuras de filantropos, ONGs, empreendedores sociais ou fundações de $3^{\circ}$ setor, por exemplo. Deste modo, há um preenchimento do Estado, que segue monitorando e gerindo as políticas sociais - exercendo uma governança -, mas elas são avaliadas à luz da lógica empresarial e são realizadas por atores muito específicos da sociedade civil - que são considerados bem-sucedidos no mercado empreendedor, que também estão organizados hierarquicamente conforme a lógica de mercado e que têm seus próprios interesses financeiros e ideológicos em jogo na sua atuação.

As políticas sociais, nessas novas configurações de Estado, não são monolíticas, mas estão sempre em processo (Harvey, 2008). Em particular, as políticas educacionais são campo de disputa e nem sempre estão em absoluto consenso com a lógica da Terceira Via. Há heranças do Estado de Bem-Estar Social, das ditaduras, há lutas democratizantes e há o neoliberalismo mais radical influenciando as políticas. No cenário atual, essas influências parecem coexistir em diferentes níveis e em diferentes lugares, em aliança com a atual social-democracia, revelando um caráter muitas vezes contraditório, híbrido e de certa forma simbiótico nas políticas educacionais, o que confunde ainda mais aquele que busca encontrar uma noção coerente do que é entendido atualmente como uma boa educação.

Mesmo com todas essas contradições e ausência de garantias, alguns efeitos concretos têm sido notados e têm dado algumas definições claras para a concepção hegemônica de qualidade da educação. Esses efeitos estão sempre conectados à crença de que aquilo que é privado ou segue a lógica do mundo empresarial é bom, e aquilo que é público ou segue a lógica do público é ruim. Essas crenças levam a duas ofensivas capitalistas: 1) a tentativa de aproximar a educação do mercado enquanto instituição e 2) a tentativa pedagógica de ensinar (ao aluno, mas também a todos os outros atores da comunidade escolar e da sociedade, como 
os leitores da Veja) que o ethos do mercado leva o aluno ao sucesso e a sociedade ao progresso, enquanto que o ethos público leva à burocracia, à ineficiência, ao parasitismo e à corrupção. Claramente, a escola é um lugar estratégico para essa ofensiva.

Esses ataques denotam o processo amplo de redefinição global que estamos acompanhando desde os anos 1970 de construção de hegemonia capitalista. Essa redefinição passa pela reestruturação do Estado, mas também pela esfera econômica, social e pessoal, e tem se constituído a partir da linguagem, como antecipou Bakhtin (2006), com a criação de novas expressões, com a rearticulação de termos e com novas formas de representação e significação. A própria importância que o termo qualidade tem adquirido em detrimento da palavra democratização é um exemplo disso, além de um léxico amplo que tem colonizado a esfera pública e a educação, com palavras como eficiência, desempenho, produtividade e resultado ocupando uma centralidade na avaliação de uma boa educação, enquanto são silenciados termos como conhecimento popular, cidadania ejustiça social. O que está em jogo atualmente, portanto, não é apenas a imposição de um sistema econômico, mas a criação de um senso de realidade, de um espaço social, político, linguístico, ideológico, fora do qual seria impossível pensar e operar (Silva, 1995). Nesse contexto, visões alternativas passam a ser suprimidas da imaginação dos sujeitos sociais e as próprias categorias discursivas que definiriam propostas contra-hegemônicas passam a ser ressignificadas, dificultando a concepção, a explicação ou o entendimento de contrapropostas. Por isso, também, reforçamos que as articulações contra-hegemônicas passam pela linguagem - é impossível imaginar uma superação dos problemas educacionais e sociais sem uma rearticulação das palavras e sem que seu uso seja conectado a significados amplamente silenciados. Entendemos, assim como Resende e Ramalho (2013), que todos os problemas sociais, assim como suas possíveis soluções, são parcialmente discursivos.

Em um contexto social de Terceira Via e neoliberalismo, é esperado que o novo vocabulário do mercado passe a operar de forma hegemônica como parâmetro para qualidade. Com a premência da linguagem do individualismo e do mercado, passa a fazer sentido o que Silva (1995, p. 15) define como "a construção da política como manipulação do afeto e do sentimento; a transformação do espaço de discussão política em estratégias de convencimento publicitário". Ou seja, passa a ser naturalizado o que se tem observado nas estratégias políticas e nas definições de interesses (em princípio) públicos, em que o convencimento e a persuasão vêm sendo ferramentas mais importantes para a tomada de decisão do que a argumentação e a contribuição coletiva, em que o indivíduo é visto menos como um cidadão e mais como um consumidor. O que vemos é que, 
atualmente, o discurso capitalista é o discurso capaz de nomear a realidade à nossa volta, constrangendo a forma como podemos pensar a sociedade e limitando que tipos de educação são imaginadas como possíveis.

Com a transformação do cidadão em consumidor, a educação passou a ser cada vez mais legitimada como um produto, em nome da liberdade de escolha. São diversos os movimentos políticos em favor da competição entre escolas públicas pelos melhores alunos. Tem se instalado, em nome de menos governo, essa nova concepção de qualidade para a escola pública. Porém, o que se vê é menos governo da coletividade escolar, e mais governo das leis de mercado (Silva, 1995) - mesmo que dentro de estruturas estatais ou misturado a elas, nas reconfigurações da Terceira Via, quando, pode-se dizer, se vê mais governança do Estado e mais governo das leis de mercado.

A concepção hegemônica de qualidade, portanto, é uma concepção comparativa, ligada à noção de riqueza (Silva, 1995). Só há qualidade da educação quando há, em outro lugar, a sua negação: a falta de qualidade. De fato, conforme Enguita (1995, p. 97), no momento em que houve a universalização do acesso à educação, percebeu-se que "a única coisa que [a educação] em segurança tinha de indiscutivelmente 'bom' era sua exclusividade, e isto foi justamente a primeira coisa que foi perdida”. Assim, historicamente o capitalismo em seus diferentes momentos vem, uma vez que o acesso ao ensino está cada vez mais universalizado, constituindo mecanismos que conservem a exclusividade da educação na forma conjuntural em que se dá a escolarização. É, afinal, a exclusividade que dá o tom da qualidade da educação nesse contexto. De acordo com Gentili (1995, p. 174), "na terminologia do moderno mercado mundial, 'qualidade' quer dizer 'excelência' e 'excelência', 'privilégio', nunca 'direito'”. Sendo assim, quando o mercado em questão é o mercado educacional, que é como a educação tem sido vista na perspectiva hegemônica, e o produto é a educação, a qualidade da educação passa a ser encarada como o privilégio que alguns recebem, ou seja, demanda que existam os desprivilegiados. A qualidade da educação, na leitura correntemente naturalizada, exige fracasso coletivo em nome do sucesso de poucos.

Desta forma, na concepção hegemônica de qualidade educacional, só há qualidade quando há, também, falta de qualidade, pois, segundo essa definição, qualidade é a negação da igualdade. Nas concepções contra-hegemônicas que têm sido silenciadas desde o fim das ditaduras, ao inverso, só há qualidade quando não há falta de qualidade, pois qualidade é a negação da desigualdade. Essa diferenciação pode também ser sintetizada na fala de Gentili:

Não existe "qualidade" como dualização social. Não existe "qualidade" possível quando se discrimina, quando as maiorias são sub- 
metidas à miséria e condenadas à marginalidade, quando se nega o direito à cidadania $\mathrm{a}$ mais de dois terços da população. Reiteremos enfaticamente: "qualidade" para poucos não é "qualidade": é "privilégio". Nosso desafio é outro: consiste em construir uma sociedade onde os "excluídos" tenham espaço, onde possam fazer-se ouvir, onde possam gozar do direito a uma educação radicalmente democrática. Em suma, uma sociedade onde o discurso da qualidade como retórica conservadora seja apenas uma lembrança deplorável da barbárie que significa negar às maiorias seus direitos. (Gentili, 1995, p. 177).

Essa fala de Gentili é elucidativa, também, porque reforça que as lutas contra-hegemônicas não se tratam de uma anulação do termo ou de um desejo desconexo da realidade de uma luta pelo fim da educação de qualidade. Trata-se de uma proposta de rearticulação do significado da palavra, aproximando-a da democracia e afastando-a do privilégio, da competição, do individualismo e do consumo. A hegemonia, como discutimos aqui, constrói-se historicamente na estrutura social, na qual as palavras ocupam uma posição de centralidade. A construção sócio-histórica da definição hegemônica de qualidade, mesmo que nas condições presentes conecte-se ao senso comum em torno da noção de riqueza e privilégio, é articulada socialmente e, por isso, não determinada ou absoluta, mas sempre em disputa.

\section{CONCLUSÃo}

O que buscamos apresentar aqui é como, através da linguagem, se articulam a produção e a reprodução de um significado hegemônico de educação de qualidade. Esse processo de hegemonização tem consequências diretas para os rumos da educação, sendo a busca por qualidade justificativa para reformas essencialmente conservadoras nos sistemas educacionais. As reformas conservadoras que temos observado na educação têm como base uma vinculação ao senso comum, aparecendo como transformações, como aumento de qualidade, enquanto se tratam de aperfeiçoamentos em um sistema que preserva e legitima as desigualdades e a injustiça. Nesse processo de articulação de sentidos em nome da hegemonia dessa lógica, a linguagem tem sido central, como aqui discutimos.

Apesar disso, queremos concluir reforçando que a linguagem é um campo de disputa. Ao mesmo tempo que articulada hegemonicamente com sentidos bem definidos na educação, pertence a toda sociedade e, por isso, é um recurso material universal que rearticula e desarticula sentidos, e assim a realidade como um todo. A linguagem ocupa uma posição de centralidade nas (não tão pequenas) conquistas educacionais brasileiras, o que se pode verificar nas rearticulações de sentidos concretas de construções educacionais contra-hegemônicas, como foi a Escola Cidadã, em 
Porto Alegre, por exemplo (Gandin, 2002). Não deixemos de recorrer a ela, portanto, nesta longa revolução (Williams, 2000).

\section{REFERÊNCIAS}

APPLE, Michael W. Ideologia e currículo. Tradução de Vinícius Figueira. 3. ed. Porto Alegre: Artmed, 2008.

BALL, Stephen J. Novos Estados, nova governança e nova política educacional. In. APPLE, Michael W.; Ball, Stephen J.; Gandin, Luís Armando (orgs.). Sociologia da educação: análise internacional. Porto Alegre: Penso, 2013. p. 177-189.

BAKHTIN, Mikhail. Marxismo e filosofia da linguagem. 12. ed. Hucitec, 2006.

CLARKE, John; NEWMAN, Janet. The Managerial State: power, politics and ideology in the remaking of Social Welfare. London: Sage Publications, 2006.

ENGUITA, Mariano F. O discurso da qualidade e a qualidade do discurso. Tradução de Tomaz Tadeu da Silva. In: Gentili, Pablo A. A.; Silva, Tomaz Tadeu da (orgs.). Neoliberalismo, qualidade total e educação: visões criticas. 2. ed. Petrópolis: Vozes, 1995. p. 93-110.

GANDIN, Luís Armando. Democratizing access, governance, and knowledge: the struggle for educational alternatives in Porto Alegre, Brazil. 2002. 296 f. Tese (Doutorado em Curriculum and Instruction) - University of Winsconsin-Madison, Winsconsin. 2002.

.Porto Alegre as a counter-hegemonic global city: building globalization from below in governance and education. Discourse-Abingdon, v. 32, p. 235-252, 2011.

GANDIN, Luís Armando; APPLE, Michael W. Can critical democracy last? Porto Alegre and the struggle over thick democracy in education. Journal of Education Policy, v. 27, p. 621-639, 2012.

GENTILI, Pablo A. A. O discurso da qualidade como nova retórica conservadora no campo educacional. Tradução de Vânia Paganini Thurler. In: Gentili, Pablo A. A.; Silva, Tomaz Tadeu da (orgs.). Neoliberalismo, qualidade total e educação: visões criticas. 2. ed. Petrópolis: Editora Vozes Ltda., 1995. p. 111-178.

GIDDENS, Anthony. A Terceira Via e seus críticos. Rio de Janeiro: Record, 2001.

HALL, Stuart. Da diáspora: identidades e mediações culturais. Tradução de Adelaine La Guardia. Belo Horizonte: Editora UFMG, 2003. 
HARVEY, David. O neoliberalismo: história e implicações. São Paulo: Loyola, 2008.

O enigma do capital e as crises do capitalismo. São Paulo: Boitempo, 2010.

JAKOBSON, Roman. Prefácio. In: Bakhtin, Mikhail. Marxismo e filosofia da linguagem. 12. ed. Hucitec, 2006.

MÉSZÁROS, István. A crise estrutural do capital. Tradução de Francisco Raul Cornejo. São Paulo: Boitempo, 2011.

PERONI, Vera. A privatização do público: implicações para a democratização da educação. In: (org.). Redefinições das fronteiras entre o público e o privado: implicações para a democratização da educação. Brasília: Líber Livro, 2013a. p. 9-32.

As relações entre o público e o privado nas políticas educacionais no contexto da terceira via. In: Currículo sem fronteiras, v. 13 , n. 2, p. 234-255, maio/ago. 2013 b.

Mudanças no papel do Estado e políticas públicas de educação: notas sobre a relação público/privado. In: Peroni, Vera; Rossi, Alexandre José (orgs.). Políticas educacionais em tempos de redefinições no papel do Estado: implicações para a democratização da educação. Porto Alegre: Editora e Gráfica Universitária, 2011.

SILVA, Tomaz Tadeu da. A "nova" direita e as transformações na pedagogia da política e na política da pedagogia. In: Gentili, Pablo A. A.; Silva, Tomaz Tadeu da (orgs.). Neoliberalismo, qualidade total e educação: visões críticas. 2. ed. Petrópolis: Vozes, 1995. p. 9-30.

WILLIAMS, Raymond. Marxismo y Filosofia. 2. ed. Barcelona: Ediciones Península, 2000. 